\title{
Extracorporeal life support as a bridge to lung transplantation-experience of a high-volume transplant center
}

Konrad Hoetzenecker, MD, PhD, ${ }^{\mathrm{a}, \mathrm{b}}$ Laura Donahoe, MD, ${ }^{\mathrm{a}}$ Jonathan C. Yeung, MD, PhD, ${ }^{\mathrm{a}}$ Sassan Azad, CRA, ${ }^{a}$ Eddy Fan, MD,${ }^{\mathrm{c}}$ Niall D. Ferguson, MD,${ }^{\mathrm{c}}$ Lorenzo Del Sorbo, MD, ${ }^{\mathrm{c}}$

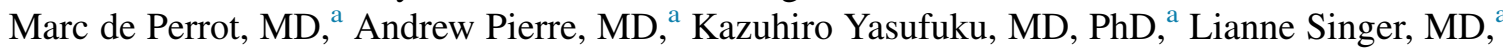
Thomas K. Waddell, MD, PhD, ${ }^{a}$ Shaf Keshavjee, MD, ${ }^{a}$ and Marcelo Cypel, MD, MSc, FRCSC ${ }^{a}$

\section{ABSTRACT}

Objectives: Extracorporeal life support (ECLS) is increasingly used to bridge deteriorating patients awaiting lung transplantation (LTx), however, few systematic descriptions of this practice exist. We therefore aimed to review our institutional experience over the past 10 years.

Methods: In this case series, we included all adults who received ECLS with the intent to bridge to LTx. Data were retrieved from patient charts and our institutional ECLS and transplant databases.

Results: Between January 2006 and September 2016, 1111 LTx were performed in our institution. ECLS was used in 71 adults with the intention to bridge to LTx; of these, $11(16 \%)$ were bridged to retransplantation. The median duration of ECLS before LTx was 10 days (range, $0-95$ ). We used a single dual-lumen venous cannula in 23 patients $(32 \%)$. Nine of 13 patients $(69 \%)$ with pulmonary hypertension were bridged by central pulmonary artery to left atrium Novalung. Twenty-five patients $(35 \%)$ were extubated while on ECLS and 26 patients $(37 \%)$ were mobilized. Sixty-three patients $(89 \%)$ survived to LTx. Survival by intention to treat was $66 \%$ ( 1 year), $58 \%$ ( 3 years) and $48 \%$ ( 5 years). Survival was significantly shorter in patients undergoing ECLS bridge to retransplantation compared with first LTx (median survival, 15 months (95\% CI, 0-31) versus 60 months (95\% CI, 37-83); $P=.041)$.

Conclusions: In our center experience, ECLS bridge to first lung transplant leads to good short-term and long-term outcomes in carefully selected patients. In contrast, our data suggest that ECLS as a bridge to retransplantation should be used with caution. (J Thorac Cardiovasc Surg 2018;155:1316-28)

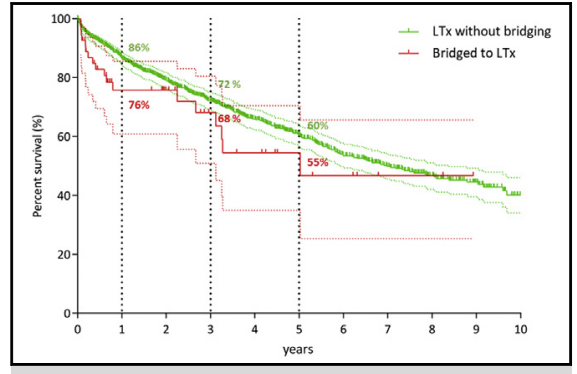

Survival of patients bridged to their first transplant versus nonbridged patients.

\section{Central Message}

ECLS bridge to first lung transplant leads to good short-term and long-term outcomes. ECLS bridge to retransplantation is challenging and thus requires strict patient selection.

\section{Perspective}

ECLS is an increasingly used technology to bridge patients to LTx. However, there is a lack of published data providing guidance for the management of this specific high-risk population of patients. This work shows the evolution of technical approaches used by our program to better meet patient physiologic needs during ECLS treatment.

See Editorial Commentary page 1329.

See Editorial page 1314.

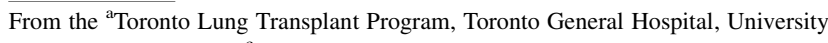
Health Network, and ${ }^{\mathrm{c}}$ Division of Critical Care Medicine, University of Toronto, Toronto, Ontario, Canada; and ${ }^{b}$ Department of Thoracic Surgery, Medical University of Vienna, Vienna, Austria.

Read at the 97th Annual Meeting of The American Association for Thoracic Surgery, Boston, Massachusetts, April 29-May 3, 2017.

Received for publication May 21, 2017; revisions received Sept 10, 2017; accepted for publication Sept 30, 2017; available ahead of print Dec 14, 2017.

Address reprints to: Marcelo Cypel, MD, MSc, FRCSC, Division of Thoracic Surgery, University Health Network, University of Toronto, 200 Elizabeth St., Toronto, Ontario, M5G 2C4, Canada (E-mail: marcelo.cypel@uhn.ca). $0022-5223 / \$ 36.00$

Copyright (c) 2017 by The American Association for Thoracic Surgery https://doi.org/10.1016/j.jtcvs.2017.09.161
The shortage of available organs continues to be a problem in lung transplantation (LTx). Although a variety of strategies have been developed to address this situation, such as

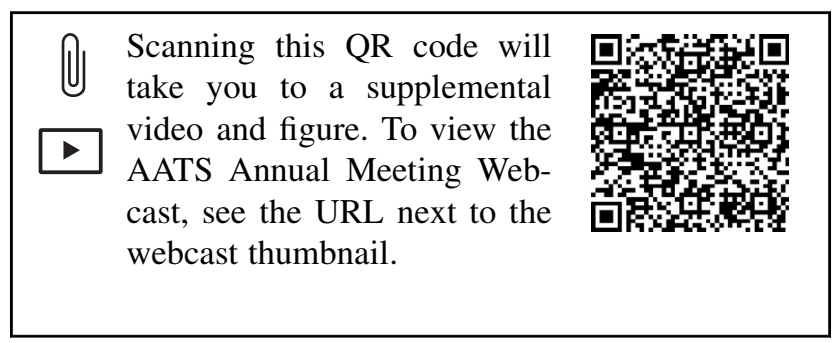




$\begin{aligned} & \text { Abbreviations and Acronyms } \\ & \text { AV }=\text { Arteriovenous } \\ & \text { CF }=\text { Cystic fibrosis } \\ & \text { CI }=\text { Confidence internal } \\ & \text { ECLS }=\text { Extracorporeal life support } \\ & \text { ECMO }=\text { Extracorporeal membrane oxygenation } \\ & \text { fem-fem }=\text { femorofemoral } \\ & \text { ILD }=\text { Interstitial lung disease } \\ & \text { IPAH }=\text { Idiopathic pulmonary arterial } \\ & \text { hypertension } \\ & \text { ISHLT }=\text { International Society for Heart and Lung } \\ & \text { Transplantation } \\ & \text { LA }=\text { Left atrium } \\ & \text { LTx }=\text { Lung transplantation } \\ & \text { PA }=\text { Pulmonary artery } \\ & \text { PGD }=\text { Primary graft dysfunction } \\ & \text { RAS }=\text { Restrictive allograft syndrome } \\ & \text { VA }=\text { Venoarterial } \\ & \text { VV }=\text { Venovenous }\end{aligned}$

accepting extended criteria donors, donation after circulatory death, and ex vivo lung perfusion, the demand continuously outstrips the available supply of organs. This results in increasing waiting times and a high mortality of $10 \%$ to $20 \%$ while waiting. ${ }^{1}$ Given these circumstances, new concepts have evolved to bridge otherwise good transplant candidates with acute deterioration to transplantation in the setting of end-stage respiratory failure. Intubation and invasive mechanical ventilation alone as a bridging strategy are suboptimal and many patients fail to reach transplantation using that approach. ${ }^{2}$

The first anecdotal use of extracorporeal life support (ECLS) as a bridge to lung transplant was reported in 1978. ${ }^{3}$ Although this first reported patient died 18 days after transplantation as a result of bronchial dehiscence, the concept of ECLS to overcome severe hypercapnia was proved a successful strategy. Nevertheless, the use of ECLS as a bridge to LTx was considered a contraindication for a long time, mainly because of the potential side effects of long-term extracorporeal support, including hemolysis, bleeding complications, stroke, severe infection, and renal insufficiency. ${ }^{4}$

Technical advances and the availability of different devices, customizable to each patient's needs, have resulted in a resurgence of ECLS bridging. This development was mainly driven by encouraging data of ECLS application in acute respiratory distress syndrome. ${ }^{5}$ Although these studies were based on a different patient population, they showed the beneficial effects of ECLS with a significantly lower rate of complications. In addition, many lung transplant centers have expanded their experience with
ECLS devices, increasingly using them for intraoperative support or in patients with severe primary graft dysfunction (PGD). ${ }^{6}$ Consequently, the practice of using ECLS as a bridge to lung transplant has gradually increased over the last decade. ${ }^{7}$ However, only a few descriptions of this practice exist, most of them limited by a small number and significant heterogeneity of patients. We therefore set out to review our institutional experience with ECLS bridging over the past 10 years.

\section{METHODS \\ Study Design}

All patients who received ECLS with the intent of bridge to lung transplant, including retransplantation, between January 2006 and September 2016 were included in this single-center retrospective analysis (Figure E1). Data were retrieved from patient charts and from our institutional ECLS and transplant databases. This study was approved by the research ethics board of University Health Network.

\section{ECLS Technique}

At the time of listing, the possibility of institution of ECLS as a bridging device was discussed for all patients who were deemed suitable for possible mechanical ventilation should they deteriorate on the wait list. Thus, a priori selection of potential ECLS bridge candidates was determined by team consensus at the time of listing. In general, preexisting multiorgan dysfunction, age $>65$ years, prolonged mechanical ventilation, uncontrolled sepsis, and other significant comorbidities (eg, body mass index $>30$, coronary artery disease, and severe deconditioning) were considered contraindications for ECLS bridging. All patients participated in supervised physiotherapy for the entire waiting period. When required, ECLS was instituted as soon as possible to avoid prolonged ventilation time and physical deconditioning.

The algorithm for choosing ECLS modes is shown in Table 1. Isolated hypercapnic respiratory failure was either corrected by pumpless femorofemoral (fem-fem) arteriovenous (AV) Novalung (Xenios, Germany), Hemolung (ALung Technologies, Pittsburgh, Pa), or a single dual-lumen cannula venovenous extracorporeal membrane oxygenation (VV ECMO, Avalon Cannula, Maquet, Germany). Based on increasing experience with the placement of single dual-lumen cannulas, this configuration was expanded to hypercapnic patients with concomitant moderate hypoxemia. In severe cases of hypoxemia, the oxygenation capacity of single dual-lumen cannula VV ECMO can be hampered by the limited flow. Thus, conventional dual-cannula VV ECMO was applied for most of these patients. Patients with idiopathic pulmonary arterial hypertension (IPAH) with right ventricle dysfunction but preserved left ventricle function were bridged using a pulmonary artery (PA) to left atrium (LA) Novalung, as previously described by our group. ${ }^{8}$ In patients with IPAH with a transient biventricular failure, a fem-fem venoarterial (VA) ECMO was generally implemented.

ECLS devices were inserted in the operating room or intensive care unit by means of percutaneous Seldinger technique for VV ECMO. Percutaneous or cutdown techniques were used for VA ECMO. In PA/LA Novalung bridged patients, femoral VA ECMO was first installed with local anesthesia to facilitate hemodynamic stability, as previously reported. ${ }^{9}$ Then the PA and LA were cannulated and connected to a pumpless Novalung device. The VA ECMO was weaned at the end of the procedure for most patients. Activated clotting time was typically maintained between 160 and $180 \mathrm{~s}$ and/or unfractionated heparin levels between 0.2 and $0.4 \mathrm{U} / \mathrm{mL}$ until the transplant. Intubated patients were aggressively weaned from the ventilator with the goal of extubation. Physiotherapy was resumed as soon as possible. ${ }^{10}$ In cases in which 
TABLE 1. Modes of extracorporeal life support and their indications for bridging

\begin{tabular}{lcccc}
\hline & $\begin{array}{c}\text { Hypercapnic } \\
\text { failure }\end{array}$ & Hypoxemic failure & $\begin{array}{c}\text { IPAH: } \\
\text { IPAH: } \\
\text { decompensated RV }\end{array}$ & No \\
biventricular failure
\end{tabular}

$I P A H$, Idiopathic pulmonary arterial hypertension; $R V$, right ventricle; $A V$, arteriovenous; $V V$, venovenous; $E C M O$, extracorporeal membrane oxygenation; $P A$, pulmonary artery; $L A$, left atrium; $V A$, venoarterial.

intubation or mobilization status changed during the bridging period, we selected the condition applied for most time to be used in this analysis.

\section{Statistical Analysis}

Categorical and continuous variables were compared using the $\chi^{2}$ test, Student $t$ test, and Mann-Whitney $U$ test, respectively. For comparing 2 binomial parameters a Boschloo test was applied. Survival curves were estimated using the Kaplan-Meier method and groups were compared by $\log$-rank tests. Survival by intention to treat was calculated from the start of ECLS until last follow-up or death. Conditional survival was calculated for patients successfully bridged to LTx using the date of LTx until last follow-up or death. Univariate analysis was performed using log-rank tests to find possible predictors for survival including primary diagnosis, type of transplant, intubation before ECLS, type of device, need for device upgrading, length on mechanical support, and ambulatory status. Multivariate analysis was not performed because of concerns related to the small number of outcome events in univariate tests.

\section{RESULTS}

\section{Patient Demographics}

Between January 2006 and September 2016, 1111 lung transplants were performed in our institution. ECLS was used in 71 adults with the intention to bridge to LTx. The proportion of patients bridged to transplantation gradually increased over time and accounted for $13 \%$ of all transplants in 2015 (Figure 1). The characteristics of ECLS-bridged patients are summarized in Table 2. The mean age was 38 years (range, 18-62 years). Interstitial

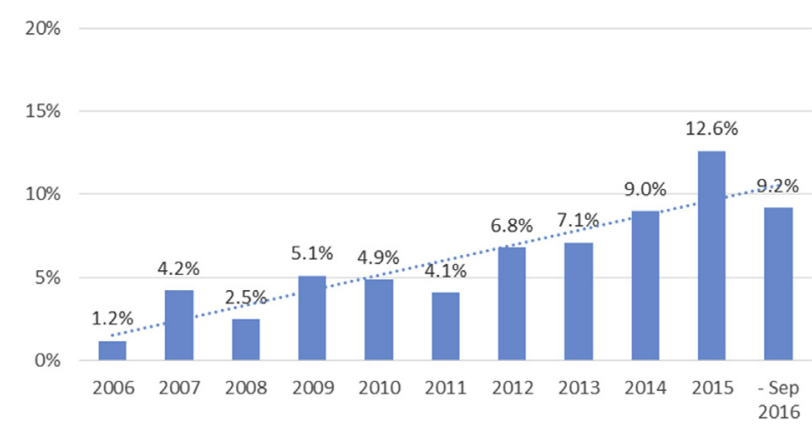

FIGURE 1. The percentage of patients bridged to transplant by extracorporeal life support in our institution. The proportion of extracorporeal life support bridging gradually increased over the years to approximately $10 \%$ of all lung transplant recipients. lung disease (ILD) was the most common diagnosis $(\mathrm{n}=26 ; 37 \%)$. Seventeen patients had cystic fibrosis and 13 patients had IPAH as the underlying disease. Eleven patients $(16 \%)$ were bridged to retransplantation. Half of the patients were already intubated, when the ECLS bridging was implemented (Table 3). For the other half, the decision for ECLS bridging was made before intubation became necessary. Most patients were in hypercapnic respiratory failure with a mean $\mathrm{PaCO}_{2}$ (partial pressure of carbon dioxide, arterial) of $88 \mathrm{~mm} \mathrm{Hg}$ (range, 25-200 $\mathrm{mm} \mathrm{Hg}$ ). In

TABLE 2. Patient clinical characteristics

\begin{tabular}{|c|c|c|c|}
\hline & $\begin{array}{c}\text { Bridge to } \\
\text { LTx } n=71\end{array}$ & $\begin{array}{c}\text { LTx without } \\
\text { bridging } \\
n=1048\end{array}$ & $\begin{array}{c}P \\
\text { value }\end{array}$ \\
\hline Age, mean (range) & $38(18-62)$ & $53(18-77)$ & $<.001$ \\
\hline Gender, $\%$, male/female & $48 / 52$ & $58 / 42$ & .101 \\
\hline Height, cm (mean $\pm \mathrm{SD})$ & $165.3 \pm 10.3$ & $168.2 \pm 9.8$ & .021 \\
\hline Weight, $\mathrm{kg}($ mean $\pm \mathrm{SD})$ & $62.3 \pm 15.5$ & $67.5 \pm 15.4$ & .006 \\
\hline BMI, $\mathrm{kg} / \mathrm{m}^{2}$, median (IQR) & $21.5(18.3-25.6)$ & $24.0(20.0-27.0)$ & .007 \\
\hline $\begin{array}{l}\text { Diagnosis, n (\%) } \\
\text { COPD } \\
\text { ILD } \\
\text { CF } \\
\text { IPAH } \\
\text { CLAD } \\
\text { Others }\end{array}$ & $\begin{array}{c}1(1.4) \\
26(36.6) \\
17(23.9) \\
13(18.3) \\
11(15.5) \\
3(4.2)\end{array}$ & $\begin{array}{c}232(22.1) \\
460(43.9) \\
164(15.6) \\
30(2.9) \\
42(4.0) \\
120(11.5)\end{array}$ & $<.001$ \\
\hline $\begin{array}{l}\text { Status at transplant } \\
1 \\
2 \\
\text { Rapidly deteriorating }\end{array}$ & $\begin{array}{r}0 \\
0 \\
71(100)\end{array}$ & $\begin{array}{l}235(22.4) \\
487(46.5) \\
312(29.8)\end{array}$ & $<.001$ \\
\hline First transplant & $60(84.5)$ & $1006(96.0)$ & $<.001$ \\
\hline Retransplantation & $11(15.5)$ & $42(4.0)$ & \\
\hline $\begin{array}{l}\text { Type of LTx } \\
\text { Double-LTx } \\
\text { Single-LTx } \\
\text { Heart-LTx }\end{array}$ & $\begin{array}{c}58(92.1) \\
3(4.8) \\
2(3.2)\end{array}$ & $\begin{array}{c}852(81.3) \\
184(17.6) \\
12(1.1)\end{array}$ & $<.001$ \\
\hline
\end{tabular}


TABLE 3. Perioperative factors of bridged patients

\begin{tabular}{|c|c|}
\hline & Values \\
\hline \multicolumn{2}{|l|}{ Respiratory status before ECLS bridging } \\
\hline Extubated, n $(\%)$ & $37(52)$ \\
\hline Intubated, n (\%) & $34(48)$ \\
\hline Last $\mathrm{PaO}_{2}, \mathrm{~mm} \mathrm{Hg}$, mean (range) & $89.9(31-316)$ \\
\hline Last $\mathrm{PaCO}_{2}, \mathrm{~mm} \mathrm{Hg}$, mean (range) & $88.2(25-200)$ \\
\hline \multicolumn{2}{|l|}{ Type of device, $\mathrm{n}(\%)$} \\
\hline Hemolung & $4(5.6)$ \\
\hline Novalung & $8(9.9)$ \\
\hline Single-cannula VV ECMO & $23(32.4)$ \\
\hline 2-cannula VV ECMO & $7(9.9)$ \\
\hline VA ECMO & $7(9.9)$ \\
\hline PA/LA Novalung & $9(12.7)$ \\
\hline Multiple devices over time & $13(18.3)$ \\
\hline \multicolumn{2}{|l|}{ Ventilation during ECLS bridging, $\mathrm{n}(\%)$} \\
\hline Extubated & $25(35.2)$ \\
\hline Tracheostomy & $14(19.7)$ \\
\hline Intubated & $32(45.1)$ \\
\hline Time on ECLS bridging, d, median (range) & $10(0-95)$ \\
\hline \multicolumn{2}{|l|}{ Survived until LTx, n (\%) } \\
\hline Yes & $63(88.7)$ \\
\hline No & $8(11.3)$ \\
\hline \multicolumn{2}{|l|}{ PGD at $72 \mathrm{~h}(\%)$} \\
\hline PGD 0/1 & 9.8 \\
\hline PGD 2 & 33.3 \\
\hline PGD 3 & 56.9 \\
\hline \multicolumn{2}{|l|}{ Postoperative ECMO, n (\%) } \\
\hline No & $36(59.0)$ \\
\hline VV ECMO & $16(26.2)$ \\
\hline VA ECMO & $9(14.8)$ \\
\hline Time to extubation after LTx, d, median (IQR) & $18(4-33)$ \\
\hline Cerebrovascular complications, $\mathrm{n}(\%)$ & $3(4.2)$ \\
\hline Acute kidney injury, n (\%) & $20(31.7)$ \\
\hline Bleeding complications, n (\%) & $22(34.9)$ \\
\hline Total hospital days before + after LTx, d, median (IQR) & $72(50-122)$ \\
\hline
\end{tabular}

Values are number (\%) except where indicated otherwise. ECLS, Extracorporeal life support; $V V$, venovenous; $E C M O$, extracorporeal membrane oxygenation; $V A$, venoarterial; $P A$, pulmonary artery; $L A$, left atrium; $L T x$, lung transplantation; $P G D$, primary graft dysfunction; $I Q R$, interquartile range.

patients with IPAH, ECLS was instituted for acute right heart failure, and thus, respiratory capacity was still largely preserved. $\mathrm{PCO}_{2}$ (partial pressure of carbon dioxide) levels were normal in most of these patients, with a mean of $38 \mathrm{~mm} \mathrm{Hg}$ (range, 25-61 mm Hg).

\section{Modes of Bridging}

The implemented modes of bridging changed significantly over time (Figure 2). Starting in 2006, the first patients were bridged with fem-fem percutaneous Novalung devices for hypercapnia. The concept of a pumpless PA/LA Novalung to bridge patients with IPAH was first applied in 2008. Single dual-lumen cannula VV

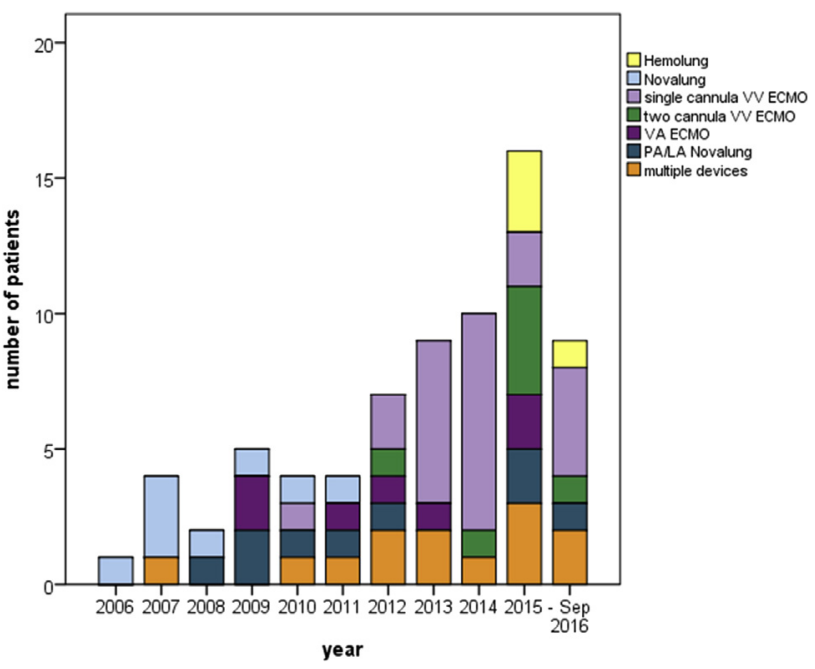

FIGURE 2. Different extracorporeal life support modes used. In the earlier period, patients were predominantly bridged by pumpless venoarterial Novalung, whereas since 2012 venovenous $(V V)$ extracorporeal membrane oxygenation $(E C M O)$ (single or dual cannula) was increasingly used to bridge patients with hypercapnic lung failure. Patients with idiopathic pulmonary arterial hypertension were bridged with a central pulmonary artery $(P A) /$ left atrium $(L A)$ Novalung beginning in 2008. VA, Venoarterial.

ECMO was implemented in 2010 and its use has increased since 2012, completely replacing the pumpless Novalung as the primary support device for $\mathrm{CO}_{2}$ removal. Since 2015, Hemolung has been used for patients with moderately increased $\mathrm{PaCO}_{2}$ levels as an extracorporeal $\mathrm{CO}_{2}$ removal device. Throughout the study period, the primary ECLS mode had to be changed in 13 patients $(18 \%)$. In 3 patients, a pumpless Novalung was upgraded to a fem-fem VA ECMO, and 4 patients were changed from a single duallumen cannula VV ECMO to a traditional dual-cannula setting. One patient had to be advanced from a VV to a VA ECMO for transient hemodynamic support. After stabilization, he was returned to a VV configuration again. In 3 patients with IPAH, mechanical support was changed from a VA ECMO to a PA/LA Novalung setting or vice versa. The remaining patient was bridged with a combination of central VA ECMO and PA/LA Novalung after bilateral pneumonectomy to treat uncontrolled sepsis. ${ }^{11}$ The median bridging time was 10 days, with a large range of 0 to 95 days on mechanical support.

\section{Awake Bridging and Ambulation}

The concept of awake bridging was first applied in 2008 in our center. Since then a structured program to mobilize patients on ECLS awaiting LTx was introduced. Twentyfive patients $(35 \%)$ were extubated and 6 tracheostomized patients $(9 \%)$ awaited their transplant completely awake. Thirty-two patients $(45 \%)$ remained intubated and 8 (11\%) remained sedated/tracheostomized throughout the bridging period. The highest proportion of awake bridging 

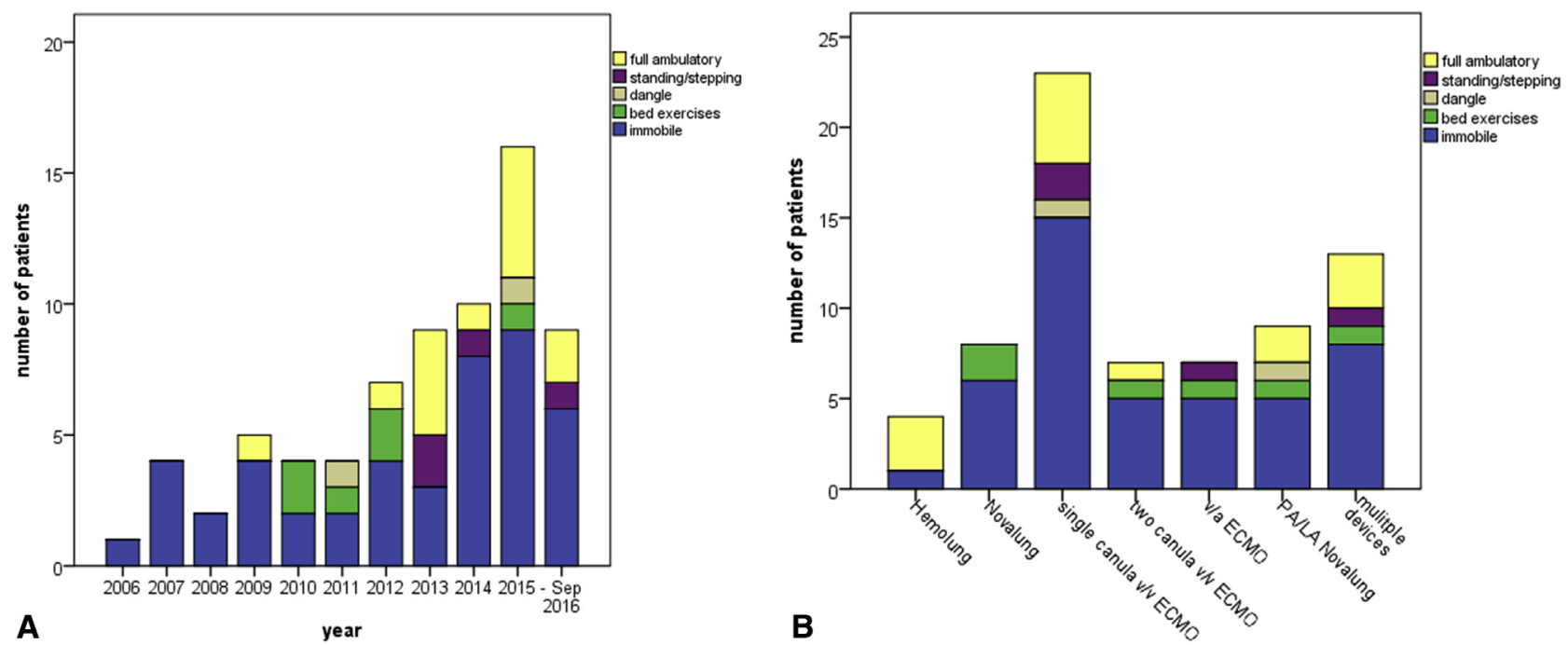

FIGURE 3. Since 2009, patients have been mobilized during their bridging period if possible. The proportion of mobile bridging was gradually increased to around $40 \%$ of patients (A). In particular, patients with extracorporeal $\mathrm{CO}_{2}$ removal devices (single-cannula venovenous [ $\mathrm{v} / \mathrm{v}$ ] extracorporeal membrane oxygenation $(E C M O)$, Novalung, Hemolung) and idiopathic pulmonary arterial hypertension bridged with central pulmonary artery $(P A) /$ left atrium $(L A)$ Novalung could be successfully mobilized (B). $v / a$, Venoarterial.

was achieved in patients with a $\mathrm{CO}_{2}$ removal device (Hemolung, single dual-lumen cannula VV ECMO) as well as patients with IPAH bridged with a central PA/LA Novalung. Twenty-six patients $(37 \%)$ were mobilized: fully ambulatory/treadmill $(\mathrm{n}=14 ; 20 \%)$, bed exercises $(\mathrm{n}=6 ; 8 \%)$, stand/steps $(\mathrm{n}=4 ; 6 \%)$, dangle $(\mathrm{n}=2$; $3 \%$, Figure 3 ).

\section{Outcome Analysis}

Sixty-three $(89 \%)$ of the patients survived to LTx. Survival rates by intention to treat (from time of device insertion) were $70 \%$ ( 1 year), 63\% (3 years) and $51 \%$ (5 years) for patients bridged to their first transplant and $42 \%$ ( 1 year), $32 \%$ (3 years), and 32\% (5 years) for patients bridged to retransplantation (Figure 4 ). Conditional

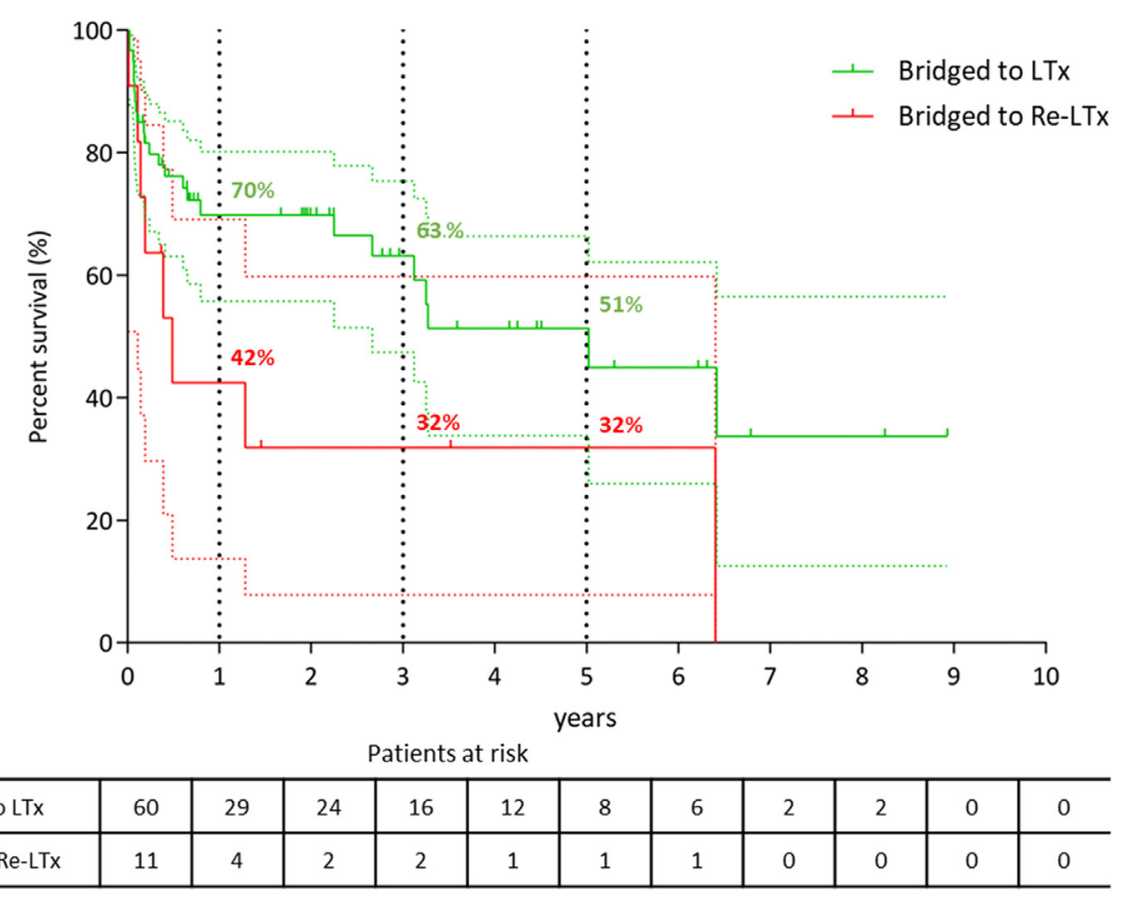

FIGURE 4. Survival curves of bridged patients by intention to treat. Patients bridged to their first transplant had good outcome with 1 -year, 3 -year, and 5 -year survival of $70 \%, 63 \%$, and $51 \%$. Survival was significantly lower for patients bridged to retransplantation (1-year, 42\%; 3-year, 32\%; 5-year, 32\%; $P=.041) . L T x$, Lung transplantation. 

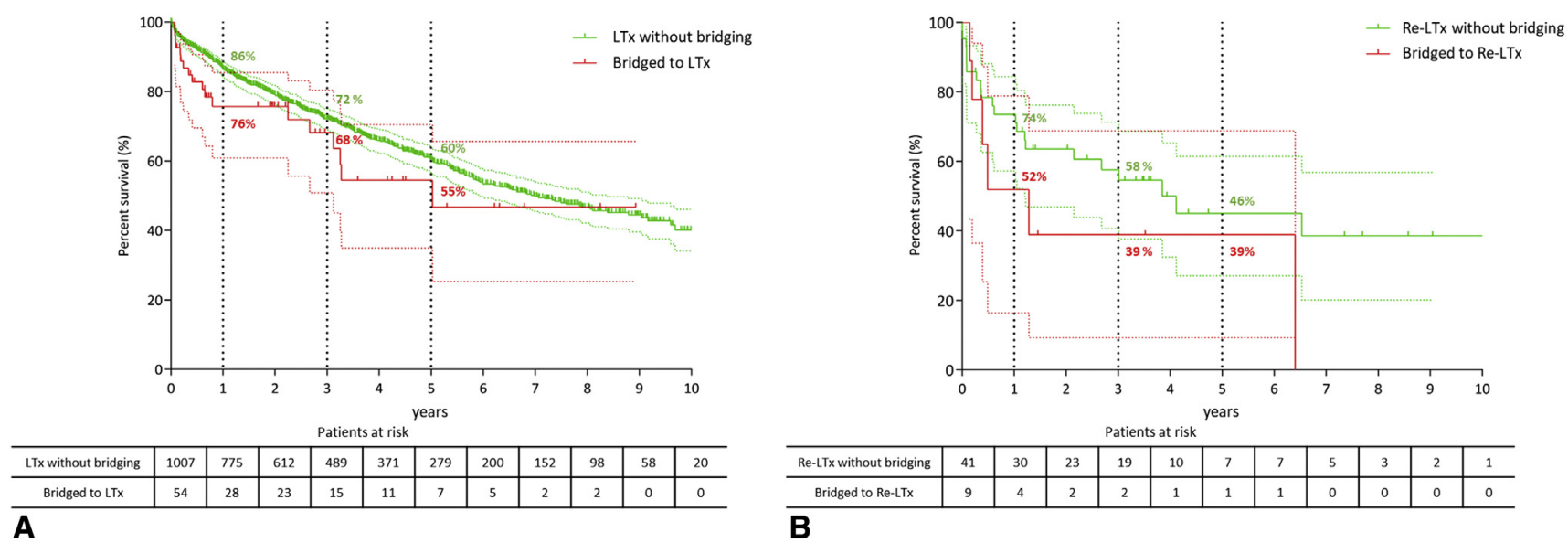

FIGURE 5. Survival curves for transplanted patients. Patients successfully bridged to their first transplant had only a slightly impaired prognosis compared with nonbridged transplant recipients (A). Survival was lower for retransplantations, both in the bridged and in the nonbridged group (B). LTx, Lung transplantation.

survival data of patients who were transplanted (excluding patients with unsuccessful bridging) are shown in Figure 5. Patients successfully bridged to their first transplant had only a slightly worse outcome compared with patients transplanted without bridging (1 year, 76\%; 3 years, $68 \%$; and 5 years, $55 \%$ vs 1 year, $86 \%$; 3 years, $72 \%$; and 5 years, $60 \% ; P=.197$; Figure $5, A$ ). Subgroup survival analysis of patients showed that the best survival rates by intention to treat were achieved in patients with cystic fibrosis (CF) and ILD, whereas patients with IPAH and chronic lung allograft dysfunction had considerably worse outcomes (Table 4).

In univariate analysis, only the type of lung transplant (primary transplantation vs retransplantation) was significantly associated with outcome (Table 5). Survival by intention to treat was significantly lower in patients undergoing ECLS bridge to retransplantation compared with first LTx (median survival, 15 months; 95\% confidence internal [CI], $0-31$ vs 60 months; $95 \% \mathrm{CI}$, $37-83 ; P=.041)$.

Next, we compared characteristics of successfully bridged patients with those of patients who died during their bridging. The only relevant difference between the 2 groups was the possibility of weaning patients from invasive ventilation (successful bridging, $\mathrm{n}=31 / 63 \quad(49.2 \%)$; unsuccessful bridging, $\mathrm{n}=1 / 8(12.5 \%) ; P=.053)$. There was also a trend toward a higher number of immobile/ sedated patients in the nonsurvivor group, but this did not reach statistical significance. The length of bridging did not differ between the 2 groups (Table 6).

\section{DISCUSSION}

This retrospective work reviews our institutional experience of ECLS bridge to LTx. Bridging was successful in $89 \%$ of patients and these patients had only a slightly worse survival compared with patients transplanted without bridging. However, patients bridged to retransplantation had a worse prognosis, with a 5-year survival of only $39 \%$ (Figure 5, B).

Our results underline previously published series showing that ECLS bridging to LTx results in good overall outcomes in experienced centers. ${ }^{12,13}$ However, given the complexity of these patients, intention-to-treat survival is generally lower compared with transplantation without bridging. ${ }^{14,15}$ Most of these very sick patients would die awaiting their transplant without ECLS. The percentage of successful bridging ranges between $50 \%$ and $83 \%$ in recent series. ${ }^{16-18}$ Patients with ILD bridged to transplant have been reported to have the worst outcome, with only half of the patients surviving until transplant and 1-year survival of only $29 \% .{ }^{19}$ However, in our series, patients with ILD did remarkably well, with an intention-to-treat 1 -year survival of $78.5 \%$.

Over the years, our ECLS strategy as well as patient selection criteria have evolved. Because complications related to ECLS technology have significantly decreased in recent years, we have liberalized inclusion criteria including older patients and patients with more comorbid conditions such as renal dysfunction.

In the early days, the prevailing support mode was a pumpless AV Novalung system applied to femoral vessels, which was primarily developed as a device for $\mathrm{CO}_{2}$ removal. Since 2012, the main device for patients with pure hypercapnic lung failure has been a VV ECMO with a single dual-lumen cannula (19-F Avalon cannula to either jugular vein or subclavian vein) or Hemolung. This concept has 2 major advantages. First, no arterial access is needed, minimizing the likelihood of severe vascular complications. Second, the single-neck cannula facilitates mobilization and exercise with both groins being spared (Video 1). 
TABLE 4. Survival outcomes according to diagnosis

\begin{tabular}{|c|c|c|c|c|c|}
\hline \multicolumn{6}{|c|}{ Patient survival (from ECLS initiation) } \\
\hline & \multicolumn{2}{|c|}{ Bridged to LTx } & \multicolumn{2}{|c|}{ LTx without bridging } & \multirow[b]{2}{*}{$P$ value } \\
\hline & Patients at risk & $\%$ & $\begin{array}{l}\text { Patients at risk } \\
\text {. }\end{array}$ & $\%$ & \\
\hline No. of patients & 71 & & & & \\
\hline \multicolumn{6}{|l|}{$\mathrm{CF}$} \\
\hline $1-y$ & $7 / 17$ & 68.4 & & & \\
\hline $5-y$ & $2 / 17$ & 54.7 & & & \\
\hline \multicolumn{6}{|l|}{ ILD } \\
\hline $1-y$ & $15 / 26$ & 78.5 & & & \\
\hline $5-\mathrm{y}$ & $3 / 26$ & 51.0 & & & \\
\hline \multicolumn{6}{|l|}{ IPAH } \\
\hline $1-y$ & $5 / 13$ & 53.8 & & & \\
\hline $5-\mathrm{y}$ & $3 / 13$ & 40.4 & & & \\
\hline \multicolumn{6}{|l|}{ CLAD } \\
\hline $1-y$ & $4 / 11$ & 42.4 & & & \\
\hline $5-\mathrm{y}$ & $1 / 11$ & 31.8 & & & \\
\hline \multicolumn{6}{|c|}{ Patients successfully bridged/transplanted } \\
\hline No. of patients & 63 & & 1048 & & \\
\hline \multicolumn{6}{|l|}{$\mathrm{CF}$} \\
\hline $1-y$ & $7 / 15$ & 77.5 & $136 / 164$ & 89.2 & .555 \\
\hline $5-\mathrm{y}$ & $2 / 15$ & 62.0 & $60 / 164$ & 64.8 & \\
\hline \multicolumn{6}{|l|}{ ILD } \\
\hline $1-\mathrm{y}$ & $14 / 24$ & 80.7 & $332 / 460$ & 83.3 & .567 \\
\hline $5-y$ & $2 / 24$ & 48.4 & $100 / 460$ & 57.9 & \\
\hline \multicolumn{6}{|l|}{ IPAH } \\
\hline $1-y$ & $5 / 11$ & 63.6 & $19 / 30$ & 80.0 & .459 \\
\hline $5-y$ & $3 / 11$ & 47.7 & $8 / 30$ & 60.6 & \\
\hline \multicolumn{6}{|l|}{ CLAD } \\
\hline $1-y$ & $4 / 9$ & 51.9 & $30 / 42$ & 73.5 & .209 \\
\hline $5-y$ & $1 / 9$ & 38.9 & $7 / 42$ & 46.3 & \\
\hline
\end{tabular}

ECLS, Extracorporeal life support; $L T x$, lung transplantation; $C F$, cystic fibrosis; $I L D$, interstitial lung disease; $I P A H$, idiopathic pulmonary arterial hypertension; $C L A D$, chronic lung allograft dysfunction.

This concept is the least invasive bridging mode and provides excellent results in patients with hypercapnic respiratory failure with or without moderate hypoxemia (in cases of hypoxemia usually 27-F or 31-F Avalon cannula are inserted). Bridging periods of over 100 days have been reported in the literature. ${ }^{20}$ The patient bridged longest in our series was awaiting retransplantation while supported with VV ECMO using a single dual-lumen cannula (19-F Avalon in right subclavian vein). He was successfully transplanted after 95 days and is alive 3.5 years after the transplantation. The median bridging time was 10 days in our cohort, and thus significantly longer compared with the periods reported by others. ${ }^{21,22}$

Many patients in our series had severe IPAH. Bridging of patients with IPAH is the most complex and the optimal bridging strategy is still a matter of discussion. Mechanical support is primarily needed to hemodynamically assist the failing right heart by reducing right ventricular preload. This support can be achieved by generating an artificial
TABLE 5. Predictors of survival by intention to treat

\begin{tabular}{|c|c|c|c|}
\hline & $\begin{array}{c}\text { Number of } \\
\text { patients }\end{array}$ & $\begin{array}{c}\text { Median } \\
\text { survival, } \\
\text { mo }(95 \% \text { CI })\end{array}$ & $\begin{array}{c}P \\
\text { value }\end{array}$ \\
\hline \multicolumn{4}{|l|}{ Diagnosis } \\
\hline COPD & 1 & - & .356 \\
\hline $\mathrm{CF}$ & 17 & NR & \\
\hline ILD & 26 & $60(37-83)$ & \\
\hline IPAH & 13 & $27(0-65)$ & \\
\hline CLAD & 11 & $15(0-31)$ & \\
\hline Others & 3 & NR & \\
\hline \multicolumn{4}{|l|}{ Type of Tx } \\
\hline First transplant & 60 & $60(37-83)$ & .041 \\
\hline Retransplant & 11 & $15(0-31)$ & \\
\hline \multicolumn{4}{|c|}{ Respiratory status before ECLS bridging } \\
\hline Not intubated & 37 & $27(1-53)$ & .051 \\
\hline Intubated & 34 & $60(28-92)$ & \\
\hline \multicolumn{4}{|l|}{ Last $\mathrm{PCO}_{2}(\mathrm{~mm} \mathrm{Hg})$} \\
\hline$<80$ & 30 & $39(13-65)$ & .274 \\
\hline$>80$ & 33 & $76(6-146)$ & \\
\hline \multicolumn{4}{|l|}{ Type of device } \\
\hline Hemolung & 4 & NR & .981 \\
\hline Novalung & 8 & $31(17-45)$ & \\
\hline Single-cannula VV ECMO & 23 & NR & \\
\hline 2-cannula VV ECMO & 7 & NR & \\
\hline VA ECMO & 7 & $60(0-145)$ & \\
\hline PA/LA Novalung & 9 & $39(4-74)$ & \\
\hline Multiple devices & 13 & $35(0-97)$ & \\
\hline \multicolumn{4}{|l|}{ Number of devices } \\
\hline 1 & 50 & $37(17-57)$ & .900 \\
\hline 2 & 17 & $39(0-82)$ & \\
\hline 3 & 4 & NR & \\
\hline \multicolumn{4}{|c|}{ Ventilation status during bridging } \\
\hline No invasive MV & 32 & NR & .827 \\
\hline Invasive MV & 39 & $39(19-59)$ & \\
\hline \multicolumn{4}{|c|}{ Ambulatory status during bridging } \\
\hline Mobile/awake & 26 & NR & .277 \\
\hline Immobile/sedated & 45 & $39(10-68)$ & \\
\hline \multicolumn{4}{|l|}{ Time on ECLS bridging } \\
\hline$<\operatorname{Median}(0-10 \mathrm{~d})$ & 36 & $60(38-82)$ & .960 \\
\hline$>\operatorname{Median}(10-95 \mathrm{~d})$ & 35 & $35(5-65)$ & \\
\hline \multicolumn{4}{|l|}{ PGD at $72 \mathrm{~h}$} \\
\hline PGD 0/1 & 5 & $37(0-85)$ & .668 \\
\hline PGD 2 & 17 & $76(35-117)$ & \\
\hline PGD 3 & 29 & NR & \\
\hline
\end{tabular}

$C I$, Confidence interval; $C O P D$, chronic obstructive pulmonary disease; $C F$, cystic fibrosis; $N R$, not reached; $I L D$, interstitial lung disease; $I P A H$, idiopathic pulmonary arterial hypertension; $C L A D$, chronic lung allograft dysfunction; $T x$, transplantation; $E C L S$, extracorporeal life support; $V V$, venovenous; $E C M O$, extracorporeal membrane oxygenation; $V A$, venoarterial; $P A$, pulmonary artery; $L A$, left atrium; $M V$, mechanical ventilation; $P G D$, primary graft dysfunction.

right-to-left shunt. A right heart unloaded in this way can recover its function, and the improved hemodynamic situation results in better end-organ perfusion. VA ECMO is a well-established bridging device for patients with 
TABLE 6. Comparison successful versus unsuccessful bridging

\begin{tabular}{|c|c|c|c|}
\hline & $\begin{array}{c}\text { Successful } \\
\text { bridging } \\
n=63\end{array}$ & $\begin{array}{c}\text { Unsuccessful } \\
\text { bridging } \\
\mathbf{n}=\mathbf{8}\end{array}$ & $\begin{array}{c}P \\
\text { value }\end{array}$ \\
\hline Age, y (mean $\pm \mathrm{SD})$ & $38.8 \pm 12.7$ & $34.8 \pm 12.1$ & .393 \\
\hline BMI, $\mathrm{kg} / \mathrm{m}^{2}$, median (IQR) & $21.3-7.3$ & $21.7-7.4$ & .822 \\
\hline $\begin{array}{l}\text { Diagnosis, n (\%) } \\
\text { COPD } \\
\text { CF } \\
\text { ILD } \\
\text { IPAH } \\
\text { CLAD } \\
\text { Others }\end{array}$ & $\begin{array}{c}1(1.6) \\
15(23.8) \\
24(38.1) \\
11(17.5) \\
9(14.3) \\
3(4.8)\end{array}$ & $\begin{array}{l}0(0) \\
2(25.0) \\
2(25.0) \\
2(25.0) \\
2(25.0) \\
0(0)\end{array}$ & .902 \\
\hline $\begin{array}{l}\text { Type of Tx } \\
\text { First transplant } \\
\text { Retransplant }\end{array}$ & $\begin{array}{r}54(85.7) \\
9(14.3)\end{array}$ & $\begin{array}{l}6(75.0) \\
2(25.0)\end{array}$ & .430 \\
\hline $\begin{array}{l}\text { Respiratory status before ECLS brid } \\
\text { Extubated } \\
\text { Intubated } \\
\text { Last } \mathrm{Po}_{2}, \mathrm{~mm} \mathrm{Hg}(\text { mean } \pm \mathrm{SD}) \\
\text { Last } \mathrm{PCO}_{2}, \mathrm{~mm} \mathrm{Hg}(\text { mean } \pm \mathrm{SD})\end{array}$ & $\begin{array}{l}\text { lging, } \mathrm{n}(\%) \\
32(50.8) \\
31(49.2) \\
90.2 \pm 46.8 \\
88.1 \pm 43.6\end{array}$ & $\begin{array}{c}5(62.5) \\
3(37.5) \\
86.2 \pm 47.8 \\
89.7 \pm 45.6\end{array}$ & $\begin{array}{l}.856 \\
.933\end{array}$ \\
\hline $\begin{array}{l}\text { Type of device, n (\%) } \\
\text { Hemolung } \\
\text { Novalung } \\
\text { Single-cannula VV ECMO } \\
\text { 2-cannula VV ECMO } \\
\text { VA ECMO } \\
\text { PA/LA Novalung } \\
\text { Multiple devices }\end{array}$ & $\begin{array}{c}3(4.8) \\
8(12.7) \\
21(33.3) \\
6(9.5) \\
6(9.5) \\
8(12.7) \\
11(17.5)\end{array}$ & $\begin{array}{l}1(12.5) \\
0(0) \\
2(25.0) \\
1(12.5) \\
1(12.5) \\
1(12.5) \\
2(25.0)\end{array}$ & .893 \\
\hline $\begin{array}{l}\text { Number of devices } \\
1 \\
2 \\
3\end{array}$ & $\begin{array}{c}44(69.8) \\
16(25.4) \\
3(4.8)\end{array}$ & $\begin{array}{l}6(75) \\
1(25.0) \\
1(25.0)\end{array}$ & .529 \\
\hline $\begin{array}{l}\text { Ventilation status } \\
\text { No invasive MV } \\
\text { Invasive MV }\end{array}$ & $\begin{array}{l}31(49.2) \\
32(50.8)\end{array}$ & $\begin{array}{l}1(12.5) \\
7(87.5)\end{array}$ & .053 \\
\hline $\begin{array}{l}\text { Ambulatory status } \\
\text { Mobile/awake } \\
\text { Immobile/sedated }\end{array}$ & $\begin{array}{l}25(39.7) \\
38(60.3)\end{array}$ & $\begin{array}{l}1(12.5) \\
7(87.5)\end{array}$ & .133 \\
\hline $\begin{array}{l}\text { Time on ECLS bridging, } \mathrm{d}, \\
\text { median (IQR) }\end{array}$ & $11(5-17)$ & $8.5(5-24.5)$ & .841 \\
\hline
\end{tabular}

$S D$, Standard deviation; $B M I$, body mass index; $I Q R$, interquartile range; $C O P D$, chronic obstructive pulmonary disease; $C F$, cystic fibrosis; $I L D$, interstitial lung disease; $I P A H$, idiopathic pulmonary arterial hypertension; $C L A D$, chronic lung allograft dysfunction; $T x$, transplantation; $E C L S$, extracorporeal life support; $V V$, venovenous; $E C M O$, extracorporeal membrane oxygenation; $V A$, venoarterial; $P A$, pulmonary artery; $L A$, left atrium; $M V$, mechanical ventilation.

IPAH. $^{22,23}$ One major disadvantage of VA ECMO is the required femoral cannulation, which confines patients in bed until the transplant and makes an ambulatory bridging impossible. Some have suggested the use of subclavian artery cannulation; however, this approach has not been widely accepted because of increased risk of stroke. In addition and more importantly, VA ECMO does not

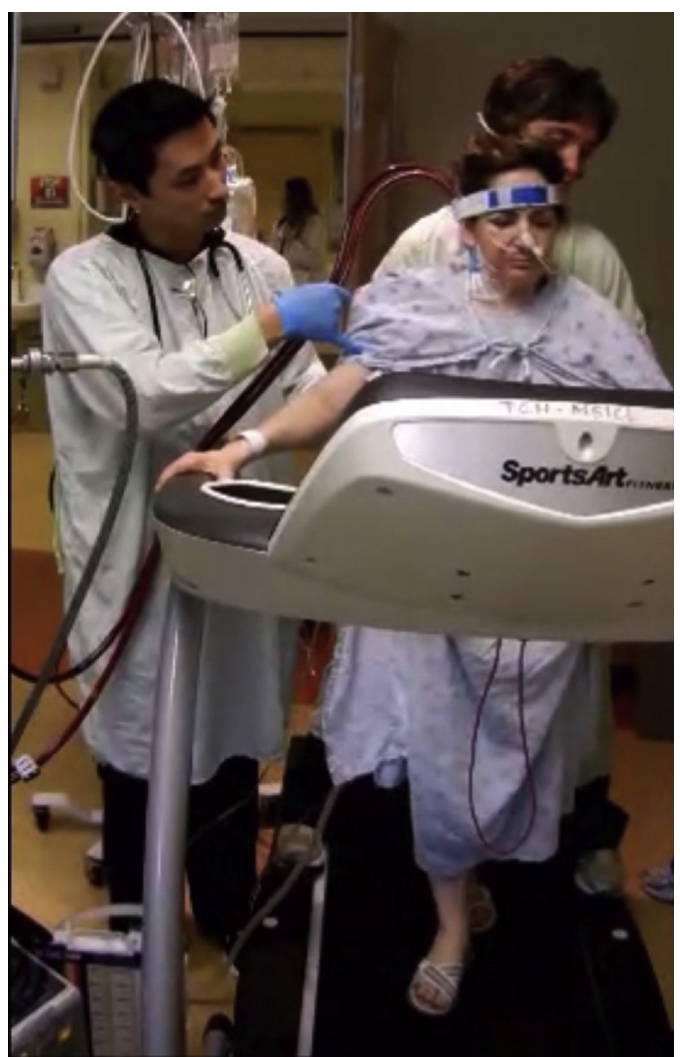

VIDEO 1. A patient bridged awake and mobilized with a single dual-lumen cannula. Video available at: http://www.jtcvsonline.org/ article/S0022-5223(17)32720-4/fulltext.

completely unload the right ventricle and normalize the physiology.

The complexity of bridging patients with IPAH is also highlighted by the survival data of this study. Outcome of patients with IPAH was significantly worse compared with other indications. Although bridging was successful in $11 / 13$ patients, 1 -year survival was low, at only $63.6 \%$ (Table 4). Perioperative management of patients with IPAH is challenging and the clinical course is often complicated. The main reason for this situation is a chronically deprived left ventricle, which is vulnerable during the early postoperative period. Several strategies have been developed to overcome this phase until the heart has adapted to the changed pulmonary vascular resistance (restrictive fluid management, early hemodialysis, prolonged inotropic support, or prophylactic ECMO prolongation).

We bridged the first patient with a PA/LA Novalung in $2008,{ }^{9}$ and since then, we have used this device in 13 adult patients. Implantation of a PA/LA Novalung usually requires a temporary fem-fem VA ECMO support. A sternotomy is performed and the cannulas for the Novalung are inserted. Special care has to be taken to minimize the risk of dislocation of the cannulas. Although this procedure is a major operation, it leads to 
significantly improved hemodynamics and a stable bridging in most cases. One of the hazards of the central cannulation is bleeding/hemothorax. In our series, 5 patients had to go back to the operation room because of significant bleeding. Recently, the Vienna group has advocated the implantation of a PA/LA Novalung through a muscle-sparing left-sided anterolateral thoracotomy, which can be incorporated in the later clamshell incision, thus avoiding unnecessary destabilization of the sternal bone. In our series, 4 patients with PA/LA Novalung needed a temporary concomitant conventional peripheral VA ECMO for hemodynamic reasons. Half of the patients with a PA/LA Novalung were bridged in an awake ambulatory setting. This concept has recently been adopted by others. ${ }^{24,25}$ Besides PA/LA Novalung and VA ECMO, there are novel approaches to bridge patients with IPAH. Based on previous animal experiments, Camboni and colleagues ${ }^{26}$ and Kon and colleagues ${ }^{27}$ have advocated an atrial septostomy (to decompress the failing right heart) and a VV single dual-lumen cannula ECMO to overcome the desaturation resulting from the artificial right-to-left shunt. However, this strategy is precarious because it critically depends on directionality of the double-lumen cannula outlet orifice, which changes easily with patient position, and also depends on the iatrogenic atrial septostomy staying open sufficiently and long enough. Hoopes et al. ${ }^{28}$ successfully tested a dual-lumen cannula that can be placed percutaneously in the right internal jugular vein and advanced to the PA. Connected to an ECMO device, this setting achieved effective right heart support. However, right ventricular assist device approaches have been typically unsuccessful in primary pulmonary hypertension.

ECLS was traditionally reserved for patients with respiratory failure refractory to maximal ventilator support. Thus, ECLS management included a deeply sedated, paralyzed, and bed-bound patient. However, we and several other groups have shown that bridging to transplantation is most successful without concomitant invasive mechanical ventilation. This concept was first propagated by the Hannover group, showing encouraging results in a mixed group of patients with hypercapnic failure and patients with IPAH, who were bridged nonintubated. ${ }^{23,29}$ Consequently, Schechter et al. confirmed this in a large UNOS (United Network for Organ Sharing) database analysis. $^{30}$

In addition, an important achievement in the recent ECLS era is the concept of ambulatory bridging. Awake ECLS facilitates ambulation and thus prevents deconditioning of the patients. Weakness acquired in the intensive care unit is considered a major contributor to increased morbidity and mortality in patients receiving long-term critical care. Strategies to reduce sedation and improve mobility protocols have been shown to significantly affect outcome. ${ }^{31}$ Initial reports on ambulation during ECLS bridging to LTx were published in $2010 .^{32}$ Only limited mobilization can be achieved with femoral cannulation, and therefore, avoiding groin cannulation is a prerequisite for full ambulation. In our series, 26 of 71 patients performed physiotherapy while waiting. Once patients have stabilized on ECLS, they are seen by a dedicated team of physiotherapists and an individualized mobilization plan is formulated.

ECLS bridging for patients awaiting retransplantation remains a controversial topic. ${ }^{33}$ In our series, the outcome of patients bridged to retransplantation was significantly worse compared with patients bridged to first transplantation. The Vienna lung transplant group has previously reported $^{34}$ that the subgroup of patients who could be bridged awake to retransplantation had a similar outcome compared with elective retransplantation. We made a similar observation in our patient cohort. Patients bridged to retransplantation either extubated or awake tracheostomized had a median survival of 15 months compared with 4 months in the intubated/sedated, tracheostomized group (per intention to treat). Because of these poor results, we continue to be selective when considering patients for ECLS bridge to a second transplant. Patients with restrictive allograft syndrome (RAS) are now rarely considered for ECLS bridge because they seem to be at high risk of perioperative complications and early death. ${ }^{35}$

In many of our patients, ECLS support was prolonged postoperatively. In 16 patients, VV ECMO and in 9 patients VA ECMO was kept in place. Over time, we have increasingly expanded protective ECLS support into the early postoperative period even in grafts with acceptable primary function. This concept aims to protect lungs in these most complex patients by facilitating lung-protective ventilation (and perfusion) strategies, thus allowing minimal additional stress on the newly implanted grafts. We consider this an important supportive measure in a phase when lungs are most prone to further reperfusion induced damage. ${ }^{36}$ Consequently, calculated PGD rates have to be interpreted with caution. According to current PGD definition (International Society for Heart and Lung Transplantation [ISHLT] Grading System), patients on ECLS are automatically assigned a PGD grade 3, which explains the high number of patients with PGD 3 in our study cohort. This finding also accounts for the discrepancy seen in survival analysis, where PGD grading had no impact on overall survival (Table 5). The latest revision of the consensus group statement of the ISHLT aims to address this problem. According to this proposal, patients in the group of prophylactic ECLS prolongation should be classified as ungradable. However, this classification requires prospective documentation of the patients' conditions and is beyond the scope of this study. 
Selecting suitable patients for ECLS bridging is a critical issue. In our transplant program, each lung transplant candidate is discussed individually by the multidisciplinary transplant team at the time of listing regarding suitability for possible ECLS bridging. Sepsis, severe frailty, neurologic impairment, or presence of multiple-organ dysfunction are usually considered contraindications for ECLS bridging. Even in our limited series, we tried to identify factors that could predict successful bridging. Although statistical significance was not reached, patients who failed an awake bridging protocol were less likely to reach transplantation (Table 6). The length of bridging did not differ between the 2 groups. This finding was consistent with previous published data from the Munich group. ${ }^{17}$

ECLS is clearly an effective tool to bridge critically ill patients to a life-saving lung transplant. With a variety of available support devices and modes, ECLS can be individualized according to each patient's needs, thus minimizing morbidity.

\section{Webcast}

You can watch a Webcast of this AATS meeting presentation by going to: https://aats.blob.core.windows. net/media/17AM/2017-05-02/RM302-304/05-02-17_Room 302-304_1613_Hoetzenecker.mp4.

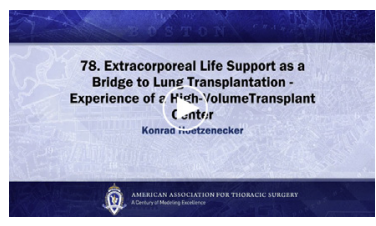

\section{Conflict of Interest Statement}

Authors have nothing to disclose with regard to commercial support.

\section{References}

1. Valapour M, Skeans MA, Heubner BM, Smith JM, Schnitzler MA, Hertz MI, et al. OPTN/SRTR 2012 Annual Data Report: lung. Am J Transplant. 2014; 14(suppl 1):139-65.

2. Elizur A, Sweet SC, Huddleston CB, Gandhi SK, Boslaugh SE, Kuklinski CA, et al. Pre-transplant mechanical ventilation increases short-term morbidity and mortality in pediatric patients with cystic fibrosis. J Heart Lung Transplant. 2007;26:127-31.

3. Nelems JM, Duffin J, Glynn FX, Brebner J, Scott AA, Cooper JD. Extracorporeal membrane oxygenator support for human lung transplantation. J Thorac Cardiovasc Surg. 1978;76:28-32.

4. Weill D, Benden C, Corris PA, Dark JH, Davis RD, Keshavjee S, et al. A consensus document for the selection of lung transplant candidates: 2014-an update from the Pulmonary Transplantation Council of the International Society for Heart and Lung Transplantation. J Heart Lung Transplant. 2015;34:1-15.

5. Peek GJ, Mugford M, Tiruvoipati R, Wilson A, Allen E, Thalanany MM, et al. Efficacy and economic assessment of conventional ventilatory support versus extracorporeal membrane oxygenation for severe adult respiratory failure (CESAR): a multicentre randomised controlled trial. Lancet. 2009;374:1351-63.

6. Mason DP, Boffa DJ, Murthy SC, Gildea TR, Budev MM, Mehta AC, et al. Extended use of extracorporeal membrane oxygenation after lung transplantation. J Thorac Cardiovasc Surg. 2006;132:954-60.
7. Hayanga AJ, Aboagye J, Esper S, Shigemura N, Bermudez CA, D’Cunha J, et al. Extracorporeal membrane oxygenation as a bridge to lung transplantation in the United States: an evolving strategy in the management of rapidly advancing pulmonary disease. J Thorac Cardiovasc Surg. 2015;149:291-6.

8. Strueber M, Hoeper MM, Fischer S, Cypel M, Warnecke G, Gottlieb J, et al. Bridge to thoracic organ transplantation in patients with pulmonary arterial hypertension using a pumpless lung assist device. Am J Transplant. 2009;9:853-7.

9. de Perrot M, Granton JT, McRae K, Cypel M, Pierre A, Waddell TK, et al. Impact of extracorporeal life support on outcome in patients with idiopathic pulmonary arterial hypertension awaiting lung transplantation. J Heart Lung Transplant. 2011;30:997-1002.

10. Wickerson L, Rozenberg D, Janaudis-Ferreira T, Deliva R, Lo V, Beauchamp G, et al. Physical rehabilitation for lung transplant candidates and recipients: An evidence-informed clinical approach. World J Transplant. 2016;6:517-31.

11. Cypel M, Waddell T, Singer LG, Del Sorbo L, Fan E, Binnie M, et al. Bilatera pneumonectomy to treat uncontrolled sepsis in a patient awaiting lung transplantation. J Thorac Cardiovasc Surg. 2017;153:e67-9.

12. Hayanga JW, Lira A, Aboagye JK, Hayanga HK, D'Cunha J. Extracorporeal membrane oxygenation as a bridge to lung transplantation: what lessons might we learn from volume and expertise? Interact Cardiovasc Thorac Surg. 2016;22:406-10.

13. Todd EM, Biswas Roy S, Hashimi AS, Serrone R, Panchanathan R, Kang P, et al. Extracorporeal membrane oxygenation as a bridge to lung transplantation: a single-center experience in the present era. J Thorac Cardiovasc Surg. 2017; 154:1798-809.

14. Inci I, Klinzing S, Schneiter D, Schuepbach RA, Kestenholz P, Hillinger S, et al Outcome of extracorporeal membrane oxygenation as a bridge to lung transplantation: an institutional experience and literature review. Transplantation. 2015 99:1667-71.

15. Orsini B, Sage E, Olland A, Cochet E, Tabutin M, Thumerel M, et al. High-emergency waiting list for lung transplantation: early results of a nation-based study Eur J Cardiothorac Surg. 2014;46:e41-47; discussion e47.

16. Javidfar J, Brodie D, Iribarne A, Jurado J, Lavelle M, Brenner K, et al. Extracorporeal membrane oxygenation as a bridge to lung transplantation and recovery. $J$ Thorac Cardiovasc Surg. 2012;144:716-21.

17. Weig T, Irlbeck M, Frey L, Zwissler B, Winter H, Preissler G, et al. Parameter associated with short- and midterm survival in bridging to lung transplantation with extracorporeal membrane oxygenation. Clin Transplant. 2013;27: E563-570.

18. Fischer S, Simon AR, Welte T, Hoeper MM, Meyer A, Tessmann R, et al. Bridge to lung transplantation with the novel pumpless interventional lung assist device NovaLung. J Thorac Cardiovasc Surg. 2006;131:719-23.

19. Biscotti M, Gannon WD, Agerstrand C, Abrams D, Sonett J, Brodie D, et al. Awake extracorporeal membrane oxygenation as bridge to lung transplantation: a 9-year experience. Ann Thorac Surg. 2017;104:412-9.

20. Kon ZN, Wehman PB, Gibber M, Rabin J, Evans CF, Rajagopal K, et al. Venovenous extracorporeal membrane oxygenation as a bridge to lung transplantation: successful transplantation after 155 days of support. Ann Thorac Surg. 2015;99:704-7.

21. Toyoda Y, Bhama JK, Shigemura N, Zaldonis D, Pilewski J, Crespo M, et al. Ef ficacy of extracorporeal membrane oxygenation as a bridge to lung transplantation. J Thorac Cardiovasc Surg. 2013;145:1065-70; discussion 1070-1.

22. Lang G, Taghavi S, Aigner C, Renyi-Vamos F, Jaksch P, Augustin V, et al. Primary lung transplantation after bridge with extracorporeal membrane oxygenation: a plea for a shift in our paradigms for indications. Transplantation. 2012; 93:729-36.

23. Fuehner T, Kuehn C, Hadem J, Wiesner O, Gottlieb J, Tudorache I, et al. Extracorporeal membrane oxygenation in awake patients as bridge to lung transplantation. Am J Respir Crit Care Med. 2012;185:763-8.

24. Mayes J, Niranjan G, Dark J, Clark S. Bridging to lung transplantation for severe pulmonary hypertension using dual central Novalung lung assist devices. Interact Cardiovasc Thorac Surg. 2016;22:677-8.

25. Schmid C, Philipp A, Hilker M, Arlt M, Trabold B, Pfeiffer M, et al. Bridge to lung transplantation through a pulmonary artery to left atrial oxygenator circuit. Ann Thorac Surg. 2008;85:1202-5.

26. Camboni D, Akay B, Pohlmann JR, Koch KL, Haft JW, Bartlett RH, et al. Venovenous extracorporeal membrane oxygenation with interatrial shunting: a novel approach to lung transplantation for patients in right ventricular failure. J Thorac Cardiovasc Surg. 2011;141:537-42. 542.e1.

27. Kon ZN, Pasrija C, Shah A, Griffith BP, Garcia JP. Venovenous extracorporeal membrane oxygenation with atrial septostomy as a bridge to lung transplantation. Ann Thorac Surg. 2016;101:1166-9. 
28. Diaz-Guzman E, Sharma NS, Wille K, Hoopes CW. Use of a novel pulmonary artery cannula to provide extracorporeal membrane oxygenation as a bridge to lung transplantation. J Heart Lung Transplant. 2016;35:1051-3.

29. Olsson KM, Simon A, Strueber M, Hadem J, Wiesner O, Gottlieb J, et al. Extracorporeal membrane oxygenation in nonintubated patients as bridge to lung transplantation. Am J Transplant. 2010;10:2173-8.

30. Schechter MA, Ganapathi AM, Englum BR, Speicher PJ, Daneshmand MA, Davis RD, et al. Spontaneously breathing extracorporeal membrane oxygenation support provides the optimal bridge to lung transplantation. Transplantation. 2016;100:2699-704.

31. Brahmbhatt N, Murugan R, Milbrandt EB. Early mobilization improves functional outcomes in critically ill patients. Crit Care. 2010;14:321.

32. Garcia JP, Iacono A, Kon ZN, Griffith BP. Ambulatory extracorporeal membrane oxygenation: a new approach for bridge-to-lung transplantation. J Thorac Cardiovasc Surg. 2010;139:e137-139.

33. Collaud S, Benden C, Ganter C, Hillinger S, Opitz I, Schneiter D, et al. Extracorporeal life support as bridge to lung retransplantation: a multicenter pooled data analysis. Annals Thorac Surg. 2016;102:1680-6.

34. Lang G, Kim D, Aigner C, Matila J, Taghavi S, Jaksch P, et al. Awake extracorporeal membrane oxygenation bridging for pulmonary retransplantation provides comparable results to elective retransplantation. J Heart Lung Transplant. 2014;33:1264-72.

35. Verleden SE, Todd JL, Sato M, Palmer SM, Martinu T, Pavlisko EN, et al. Impact of CLAD phenotype on survival after lung retransplantation: a multicenter study. Am J Transplant. 2015;15:2223-30.

36. Broccard AF, Hotchkiss JR, Kuwayama N, Olson DA, Jamal S, Wangensteen DO, et al. Consequences of vascular flow on lung injury induced by mechanical ventilation. Am J Respir Crit Care Med. 1998;157:1935-42.

Key Words: bridging, ECMO, lung transplantation

\section{Discussion}

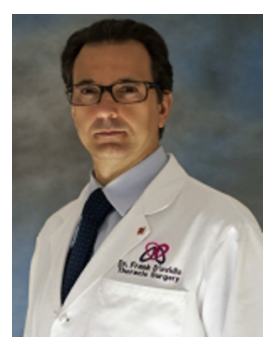

Dr Frank D'Ovidio (New York, $N Y$ ).

Thank you for allowing me to discuss this paper. Konrad, thanks for this opportunity as well as congratulations for the nice presentation and thanks for allowing me to have a look at the paper well ahead of time.

Your experience as well as all the reports spans different clinical scenarios which all have significant differences in the implications and outcomes. So what I will try to do is span it through them a bit with a few questions and a few points.

I noticed in one of your slides you are showing the increased use of tracheostomy, and I actually want to drill down on that a bit. These patients are in a good portion immobile or partially immobile and likely their normal pulmonary toilet, the physiologic pulmonary toilet that comes from daily activity is not well maintained. So should we advocate, and some centers are advocating, for a tracheostomy, particularly in the $\mathrm{CF}$ and bronchiectasis so to maintain that toilet as much as possible, trying to minimize the ventilation or allowing nocturnal ventilation to rest them and, as well, have them work hard during the day. Do you have any strategies to that? How many ECLS for hypercapnia evolved from a VV to a VA because of pneumonia that developed in a patient that wasn't tracheostomized?

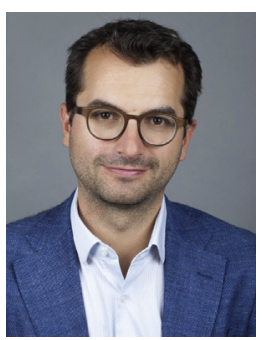

Dr Hoetzenecker (Toronto, Ontario, Canada). It has been our policy for the last few years to tracheostomize our bridging patients early. Whenever a patient cannot be extubated within 48 hours after ECLS start, we would tracheostomize him or her nowadays. This facilitates bronchial toilet, as you mentioned, and in fact in many of those patients we could reduce respiratory support. Often, we could wean them totally from invasive ventilation and bridge them in an awake setting.

Some of our CF or IPF patients, nevertheless, developed pneumonia. Usually those patients were bridged with VV devices, and if I recollect correctly, we only had to upgrade VV devices during periods of pneumonia in two patients. One of them was escalated to a VAV setting and could be downgraded again after he had overcome his infection. The second patient was a young CF patient who deteriorated and went into septic shock. She received a bilateral pneumonectomy and was bridged during the following five days with a central VA-ECMO and a central PA/LA Novalung device.

Dr D'Ovidio. Shifting gears and focusing a little bit on the ECLS, on hypercapnia, now with the new technologies that have evolved, actually in your series you experienced the Novalung for hypercapnia and then you shifted to the double-lumen Avalon cannula and then the last couple of years you are implementing the Hemolung as a $\mathrm{CO}_{2}$ dialysis.

How do you see us using in the future this new technology, how are we going to implement it? In your paper you are indicated for moderate hypercapnia to implement the $\mathrm{CO}_{2}$ dialysis. Is moderate too low or should we use it for high, elevated $\mathrm{PCO}_{2} \mathrm{~S}$ to bring it down to a moderate level, to adjust the $\mathrm{pH}$, and then maybe allow them to accommodate? Do you have an algorithm that you are going to implement?

Dr Hoetzenecker. $\mathrm{CO}_{2}$ levels are not a primary decision-making criteria on their own. More important is actually the clinical condition of a patient. A lot of our $\mathrm{CF}$ patients have very high $\mathrm{CO}_{2}$ levels but they manage to maintain their $\mathrm{pH}$ levels with intermittent noninvasive ventilation strategies. So we nowadays would put patients on $\mathrm{CO}_{2}$ removal devices whenever they are too sick to ambulate or when they are in the need of continuous nonmechanical ventilation. I think that is the right time point to consider implanting those $\mathrm{CO}_{2}$ removal devices.

Dr D'Ovidio. Lastly, looking at ECLS for pulmonary hypertension, can you give us a little more information on how you implement the PA/LA model? Do you have a range of 
$\mathrm{pH}$ that you target or do you decide based on levels of right ventricle failure? Which parameters do you use to guide that decision? And how many given these parameters required a concomitant VA-ECMO, not for development of biventricular failure, which is one of the indications that you have brought forward, but more so for an inadequate support given from the PA/LA system secondary to $\mathrm{pH}$, pulmonary artery hypertension that wasn't high enough to maintain the model and not be able to surpass the intrinsic resistance to the PA/LA model?

Dr Hoetzenecker. We don't target a specific pulmonary arterial pressure as an indicator for putting patients on PA/ LA Novalung, since when they deteriorate they usually don't have a Swan-Ganz catheter in place. So what we primarily look at is when a patient needs inotropic support or when there are signs of secondary organ dysfunction like a rise in the creatinine levels or a rise in the liver function parameters. That would be the time point to start thinking about putting patients on an ECLS device.

In regard to the strategy we use for implementing PA/LA Novalung, we usually put patients first on peripheral VA-ECMO in local anesthesia so that they can tolerate general anesthesia, then perform a sternotomy and insert the PA/ LA Novalung, and then slowly wean them from their peripheral VA-ECMO over the first two, three postoperative days.

Actually, out of our 12 patients, nine have tolerated this strategy quite well. Only three had to be maintained on peripheral VA-ECMO, one of them due to significant arrhythmias; the other ones had bi-ventricular failure, requiring a VA support.

Dr D'Ovidio. And the last question just to see what the future is, given the very quick evolution of technologies, what would be the next evolution of the PA/LA model?

Dr Hoetzenecker. The PA/LA model has already been refined. We do not necessarily require a sternal fissure for putting in those devices. There are already groups advocating a kind of minimally invasive left-sided anterolateral thoracotomy for inserting the central cannulas, which usually make things easier in regard to a later transplantation. I believe, this is the way to go.

Dr D'Ovidio. Thank you.

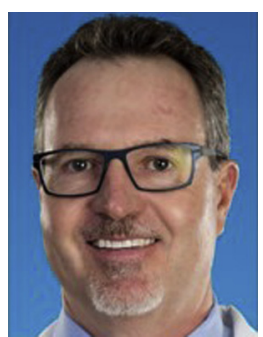

Dr Ross Bremner (Phoenix, Ariz). Congratulations and thank you to the Toronto group for their leadership in this area and very nicely presented.

In our own experience we have noted that these patients are really critically ill and it is hard to get them ambulant, and congratulations that you did succeed in getting a lot of these patients at least participating, because they generally are really critically ill. As a result of them being so sick at the time of transplant, we have noted that their length of stay after surgery is usually longer and more of them end up going to a rehabilitation center, although their one-year functional status has been excellent.

Can you share your experience with those 2 parameters?

Dr Hoetzenecker. I think in terms of ambulation it is very important to have a dedicated physical therapist team practicing with the patients during the waiting period to avoid deconditioning. Our physical therapists actually see patients twice daily. Of course, ECLS bridged patients are very complex and they have a prolonged postoperative course, so many of them eventually require rehabilitation thereafter as well.

Dr Bremner. Do you have any functional data long term? Your survival looks pretty good, but are these patients very functional at a year or two after transplant?

Dr Hoetzenecker. No, I haven't. This was not part of this analysis.

Dr Bremner. Thank you.

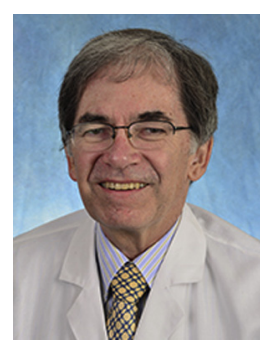

Dr Thomas E. Egan (Chapel Hill, $N C$ ). That was a nice presentation, but you have a couple of problems. One is there is not nearly enough donors, and in fact I believe the donors per million rate in Canada is well below that in the United States and well below many European countries. Your use of heroic efforts to keep people alive until transplant has increased. What are you going to do 10 years from now when your hospital is full of everybody on ECMO?

And the second question is, in the absence of a lung allocation score, how do you decide which of all these people that are on ECMO you are going to put a lung into when you finally get one of those donors that are more rare in Canada than in some other country?

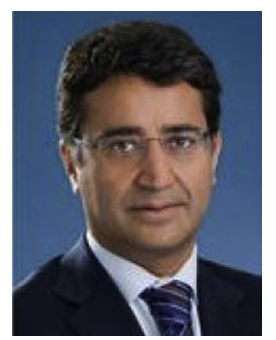

Dr Shaf Keshavjee (Toronto, Ontario, Canada). In the interest of time I will answer that for Konrad. You make it sound as if we are ridiculously putting everybody on ECMO in the hospital, which we are not doing, but I do think that there are certain patients that we can save that can't wait until they get a lung transplant. You remember in the early experience in Toronto, ECMO bridge to transplant was a horrible failure, and now, as you have seen from these results, with well selected patients you can pull it off. Over the last 2 decades we have increased the number of transplants we do by $10 \%$ every year, and we are going to keep making more organs available.

So, yes, ECMO is a failure of organ availability and I think you need to work on both sides, because making organ availability and changing culture and society is not going to help the patient who is sick today.

Dr Hoetzenecker. I think at the end of the day the strongest argument is basically what this presentation has shown 
and what others have shown before: The overall survival is similar to the non-ECLS bridged patients.

Dr Keshavjee. And we are being selective. If we had more organs, the 65-year-olds and so on would also have a chance at life where we don't really apply such advanced therapies in those groups.

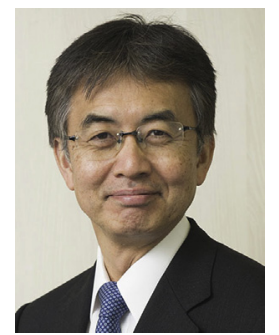

Dr Hiroshi Date (Kyoto, Japan). Konrad, if I saw it correctly, your incidence of PGD grades 2 and 3 were between 80 and $90 \%$ for this cohort, yet your short- and long-term survival is comparable to patients who were not bridged to transplantation. Can you comment on that?

Dr Hoetzenecker. The PGD rates were actually between $40 \%$ and $50 \%$.

Dr Keshavjee. Remember, for this report we used the current ISHLT (International Society for Heart and Lung Transplantation) grading, and being on ECMO is defined as PGD 3. So until we change the international score that's where we are at.

Dr Date. But you had PGD 2 and 0 and 1 as well if I saw it correctly.

Dr Keshavjee. Right, but then they didn't come out of the OR on ECMO, right, so that was the whole thing. Clearly the people bridging in have a higher likelihood of coming out on ECMO and we tend to do it prophylactically, but then they are automatically PGD 3 and our program grades it that way for now.

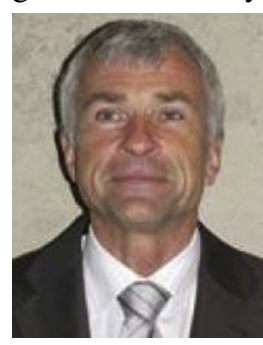

Dr Walter Klepetko (Vienna, Austria). Great series. It also includes I believe the largest series of PA/LA bridging patients. One thing I would like to ask you, Konrad, did you look at how many patients you were able to run this without pump support, I mean having a pump in the PA/LA circuit, not an additional venoarterial ECMO for the installation procedure, and in how many patients you had to upgrade it to a useable pump?

Dr Hoetzenecker. Only one patient had to be upgraded; 11 of these 12 patients didn't require a pump.
Dr Keshavjee. And no pump on the right side. The one patient he is talking about was the one who had left ventricular failure.

Dr Klepetko. One more additional question. I realize that your results with bridging for retransplantation are very good. When we analyzed our retransplantations, we realized that those patients having 6 or 7 retransplants who were bridged in an awake status had the same good outcome like the elective retransplantations whereas the nonawake retransplantations had a really very poor outcome. So we more or less consider that as an exclusion criteria if you are unable to get the retransplantation in an awake status. How are you handling that?

Dr Hoetzenecker. We actually had similar results when looking at the Toronto data. Patients bridged to retransplantation in an awake and mobile setting had the best survival and survival was completely comparable to non-bridged retransplantation patients

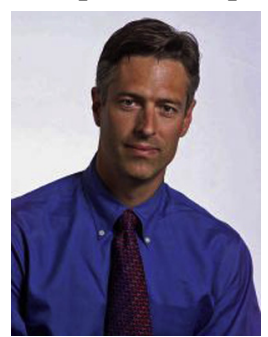

Dr R. Duane Davis (Durham, NC). This is going to be a follow-up on this. Where was it futile? We all know we can do it. It is more the question when should we not do it? You raised an issue of the RAS. I am not sure that you had actually broken it out. But what are the criteria on which we shouldn't go? And I only bring that up because I come to a meeting and they pop 2 more of our patients on ECMO and they are over 65 , and the question is, when are we really doing futile care versus when are we doing appropriate care, and are there any things from your experience and which you have learned where you would say, no, we just don't do this anymore?

Dr Hoetzenecker. I think the RAS population is definitely a group of patients that shouldn't be bridged, and not because they couldn't survive the bridging period. Only one of our RAS patients actually died during waiting for lung transplant, but due to the perioperative difficulties none of them survived the first year after transplantation.

The second indication is patients bridged to retransplantation for primary graft failure. Those patients shouldn't be bridged to a rescue retransplantation. 


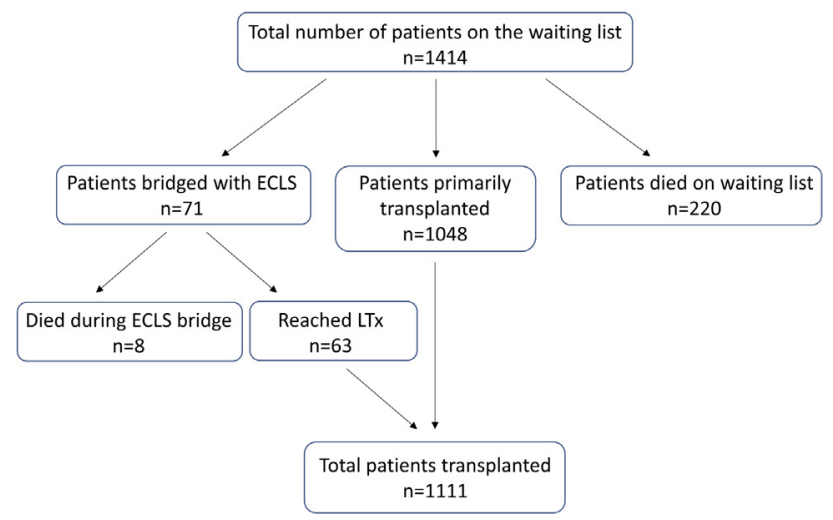

FIGURE E1. Flow chart of patients included in the study. ECLS, Extracorporeal life support; $L T x$, lung transplantation. 